\title{
ARTICLE
}

\section{Preliminary evaluation of decay heat in a HCPB DEMO fusion reactor}

\author{
Shanliang Zheng*, David Ward, Raul Pampin and Lee W. Packer \\ CCFE, Culham Science Centre, Abingdon, Oxfordshire, OX14 3DB, United Kingdom
}

\begin{abstract}
In previous studies, energy generation in a fusion DEMO reactor was estimated by accounting for prompt heat production only, neglecting the decay heat generated from the decay of radioactive isotopes. In this work, based on a helium-cooled pebble bed (HCPB) ceramic blanket which is one of the European DEMO concepts, the decay heat generated in different components is estimated as a function of cooling time is performed in order to assess its contribution. The code system HERCULES, by coupling the MCNP particle transport and the activation inventory FISPACT, is used for the calculation of prompt energy deposition and decay heat for all components in the HCPB DEMO reactor. It is found that, relative to fusion power of 2.7GW, the activated nuclides generated decay heat are $<3 \%$ at the cooling time of 1 second assuming a power plant operation scenarios. This study suggests that the material selection has a significant impact on decay heat.
\end{abstract}

Keywords: fusion DEMO reactor; HCPB; decay heat; HERCULES; FISPACT

\section{Introduction}

Power generation is one of the key functions that need to be demonstrated in a DEMO reactor in order to achieve the ultimate goal of fusion energy: to attain a commercial fusion power plant to supply electricity. In previous studies [1-4], only prompt heat production was accounted for in power production for a D-T fusion power plant. Decay heat was neglected, even though it could be an important contribution to heating of components, especially in in-vessel of a tokamak device, such as the first wall, blanket and divertor. Decay heat is produced from the decay of radioactive isotopes that have been activated by neutrons in a radiation environment e.g. within a D-T fusion DEMO reactor.

An accurate prediction of the total decay heat and its time dependence is essential for determining the heat removal requirements after reactor shutdown, during transportation and storage of the radioactive materials, and also the contribution to the energy production of a DEMO reactor. A DEMO fusion reactor model adopted in the work and calculation tools are presented in Section 2. In Section 3, contribution of estimated decay heats generated in different components to the fusion power is assessed as a function of cooling time. Section 4 provides a summary.

\section{Model and tools}

In this work, the reference design for DEMO, proposed in 2009 at CCFE [5], is employed as the base

*Corresponding author. Email: Shanliang.Zheng@ccfe.ac.uk model. The blanket design used is a helium-cooled pebble bed (HCPB) ceramic concept which is one of the breeding blanket module concepts in European DEMO study [6]. The tritium breeder is $\mathrm{Li}_{4} \mathrm{SiO}_{4}$ with beryllium as the neutron multiplier. The reduced activation ferritic-martensitic steel EUROFER acts as the structural material cooled by helium gas. The basic parameters of the HCPB DEMO reactor are listed in Table 1.

Table 1. Basic parameters of HCPB DEMO reactor.

\begin{tabular}{lc}
\hline Parameter & Value \\
\hline Fusion power (GW) & 2.7 \\
Major radius (m) & 8.50 \\
Minor radius (m) & 2.83 \\
Elongation & 1.66 \\
Triangularity & 0.33 \\
Radial shift & 0.0 \\
Peaking factor & 7.0 \\
Plasma temperature $(\mathrm{keV})$ & 20.6 \\
\hline
\end{tabular}

The code system HERCULES [7], which couples the particle transport code MCNP [8] and the activation inventory code FISPACT [9], is used for the calculation. HERCULES can evaluate the prompt energy deposition with MCNP and the IAEA fusion nuclear data library FENDL-2.1 [10], and the decay heat with FISPACT and the activation data library EAF2007 [11], for all components in the neutronics calculation model of the HCPB DEMO reactor. This model is a 90-degree toroidal sector defined in a two-dimensional (2D) model. It was developed based on a template produced within HERCULES to simulate the HCPB DEMO reactor. It 
should be noted that toroidal ports are not included in this model. The vertical cross section view of the MCNP model is shown in Figure 1. The material compositions and the component weights are given in Table 2. The quantities of radioactive isotopes are dependant on irradiation time and operation scenario assumptions. In this work, the following five operation scenarios are assumed in order to assess a pulsed DEMO [12-14] as well as a steady-state condition.

1) 8-hour irradiation at full power operation;

2) 1-month irradiation at full power operation;

3) 6-month irradiation at full power operation;

4) 30-year irradiation: in each year, half year on at full power operation and half year off in maintenance (50\% availability);

5) 30-year irradiation in a European fusion PPCS (Power Plant Conceptual Study) model B type scenario [15-17]: 2.5 years at full power, 2 months maintenance, 2.5 years at full power, 10 months maintenance, repeat 5 times (85.7\% availability).

In this work, we assume that components are not replaced.

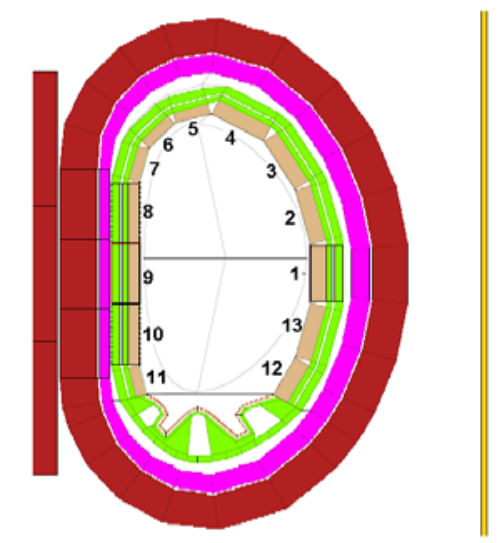

Figure 1. MCNP model of HCPB DEMO reactor.

Table 2. Materials compositions in HCPB DEMO reactor.

\begin{tabular}{lll}
\hline Component & Material Composition (vol.\%) & $\begin{array}{l}\text { Mass } \\
\text { (ton) }\end{array}$ \\
\hline First Wall & $\begin{array}{l}\text { CuCrZr 5\%; EUROFER 90\%; } \\
\text { He-gas 5\% }\end{array}$ & 191 \\
Blanket & $\begin{array}{l}\text { Be 55\%; EUROFER 10\%; } \\
\text { Li4SiO4 15\%; He-gas 20\% }\end{array}$ & 1456 \\
Back plate & EUROFER 80\%; He-gas 20\% & 1794 \\
Shield & EUROFER 80\%; He-gas 20\% & 2826 \\
Vacuum Vessel & Inconel-718 80\%; He-gas 20\% & 9154 \\
Divertor Armour & Tungsten 100\% & 151 \\
Divertor_Structure & Tungsten Oxide 80\%; He-gas & 625 \\
Divertor_Base & EUROFER 80\%; He-gas 20\% & 279 \\
Divertor_Support & EUROFER 80\%; He-gas 20\% & 853 \\
Divertor_Shield & EUROFER 80\%; He-gas 20\% & 597 \\
\hline
\end{tabular}

\section{Results and discussion}

\subsection{Basic neutronics parameters}

In a D-T fusion DEMO reactor, tritium self-sufficiency is an essential requirement. The total tritium breeding ratio (TBR) is evaluated to be $\sim 1.12$ in this HCPB DEMO reactor model. Relative to the fusion power of $2.7 \mathrm{GW}$, and considering that the D-T fusion neutrons carry $80 \%$ of the energy from the fusion plasma chamber into materials (i.e. 2.16 GW), MCNP calculations estimate a total of $\sim 3.0 \mathrm{GW}$ power generated from the prompt neutron reactions in the tokamak device. This power is distributed throughout all components as shown in Table 3, including the first wall, blanket, divertor, shielding, vacuum vessel and magnetic field coils. This results in an energy multiplication factor of $\mathrm{M} \approx 1.39$, which is defined as the ratio of total prompt neutron and photon energy deposition in all components of the reactor to the fusion neutron energy (which is $80 \%$ of the total fusion power). The first wall and blanket are the components to obtain most of the neutron energy deposition, $\sim 80 \%$ of the total neutron energy deposition in the tokamak device. The divertor carries $\sim 16 \%$ neutrons energy in the model used in this work.

Table 3. Nuclear heat and energy multiplication factor in components.

\begin{tabular}{lcc}
\hline Component & $\begin{array}{c}\text { Nuclear heat } \\
(\mathrm{MW})\end{array}$ & $\begin{array}{c}\text { Energy multiplication factor } \\
(\mathrm{M})\end{array}$ \\
\hline FW & 293.3 & 0.14 \\
\hline Blanket & 2103.6 & 0.97 \\
\hline Back plate & 79.4 & 0.04 \\
\hline Shield & 19.8 & 0.01 \\
\hline Vessel & 28.9 & 0.01 \\
\hline Divertor & & \\
Armour & 131.8 & 0.06 \\
Structure & 244.1 & 0.11 \\
Base & 38.1 & 0.02 \\
Support & 43.1 & 0.02 \\
\hline Shield & 18.9 & $8.77 \mathrm{E}-3$ \\
\hline TFC & 0.5 & $2.19 \mathrm{E}-4$ \\
\hline Solenoid & $7.21 \mathrm{E}-6$ & $3.34 \mathrm{E}-9$ \\
\hline Cryostat & $1.25 \mathrm{E}-5$ & $5.77 \mathrm{E}-9$ \\
\hline Total & 3001.5 & 1.39 \\
\hline
\end{tabular}

\subsection{Total decay heat}

Each irradiation scenario, total decay heats at the specified cooling time are evaluated: 1 second, 1 hour, 10 hours, 1 day, 3 days, 7 days, 12 days, 21 days, 30 days, 3 months, 6 months and 1 year. As shown in Figure 2, 40.6 MW, 56.8 MW, 60.3 MW, 70.2 MW and 77.9 MW of decay heats are released from the radioactive nuclides at cooling time of 1 second after the corresponding irradiation durations of 8 hours, 1 month, 6 months, 30 years and the same operation scenario as PPCS-B model. In all the cases, the neutron source power remains at $2.16 \mathrm{GW}$. All the decay heats are estimated assuming the reactor is shutdown. Relative to the fusion power of $2.7 \mathrm{GW}$, the fractions of decay heat at all the operation scenarios (shown in Figure 3) are less than $3 \%$ at 1 second after the shutdown. After 1 day cooling time, the decay heats do not contribute more than $1 \%$ relative to the total fusion power of $2.7 \mathrm{GW}$. At 
1 year cooling the decay heats decrease by one more order of magnitude. It is concluded that decay heat does not play significant role in the energy multiplication.

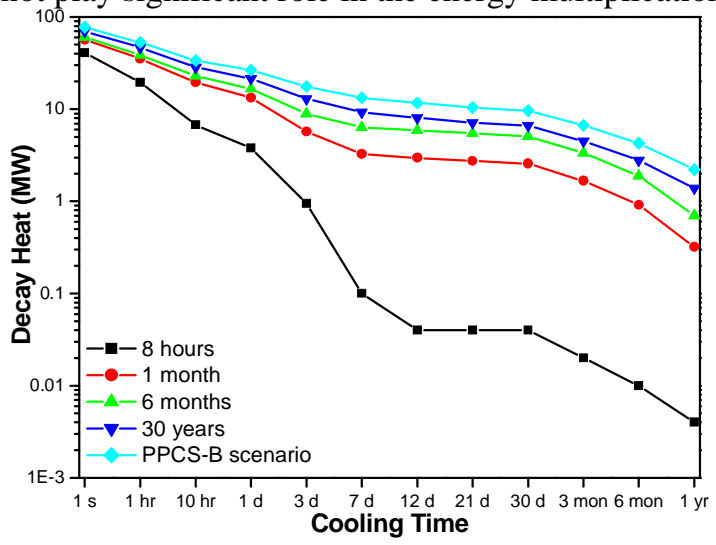

Figure 2. Total decay heat in different irradiation scenarios.

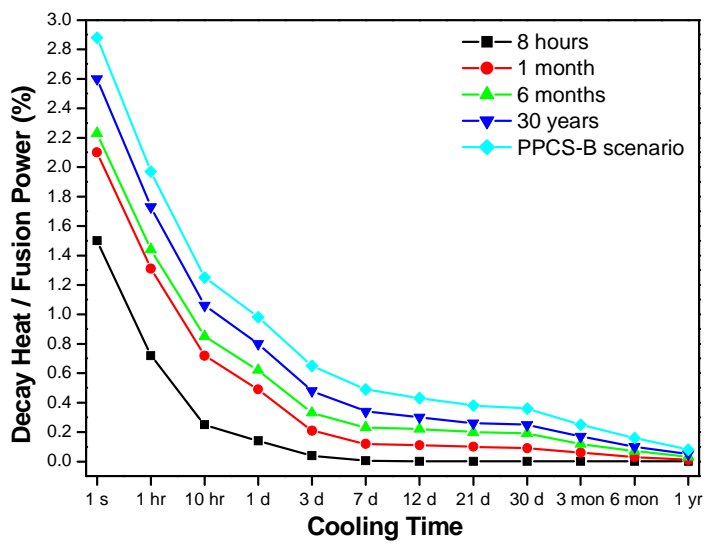

Figure 3. Fractions of decay heat relative to fusion power.

\subsection{Component decay heat}

The decay heat is spread throughout the different components similarly to the prompt heat (shown in Table 3). In order to evaluate how much heat was neglected in previous studies, the percentages of the decay heat to the prompt heat after the different irradiation histories are shown in Figure 4 and Figure 5. Because the decay heat drops rapidly with cooling time, results in two cooling times are presented, 1 second and 1 hour. In general, the decay heat fractions in the divertor armour and structure are more than those in the remaining components. $\mathrm{W}-187$ is one of the dominant radioactive isotopes for decay heat in the divertor armour ( $\sim 1 \%$ at $1 \mathrm{~s}$ and $\sim 99 \%$ at $1 \mathrm{~h}$ ) where the highest ratio exists in the divertor structure, where Re-186 and Re-188 contribute significantly to the total decay heat after 30 years irradiation. The decay heats in the blanket and vacuum vessel are smaller than all other components. Radionuclide contributions include a widely spread variety of radioactive isotopes, and no outstanding contributions from particular isotopes are highlighted here. In the components which contain EUROFER (in this model, the components are defined as FW, back plate, shield, divertor structure, divertor base, divertor support and divertor shield), Mn-56 (half-life 2.57 hr) gives a contribution more than $60 \%$ at cooling times of $1 \mathrm{~s}$ and $1 \mathrm{~h}$.

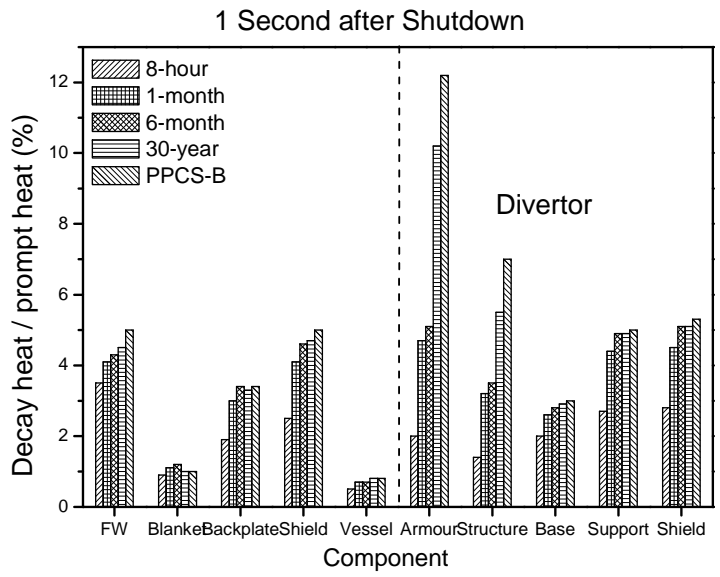

Figure 4. Percentage decay heat to prompt heat at 1 second of cooling time.

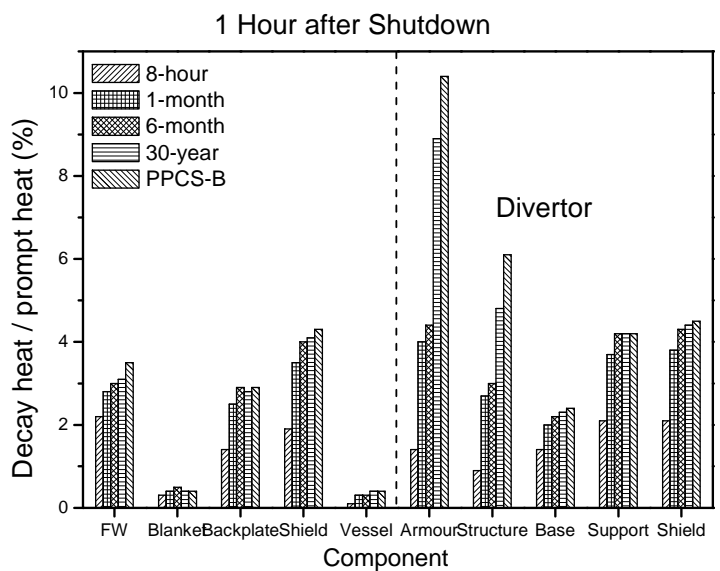

Figure 5. Percentage decay heat to prompt heat at 1 hour of cooling time.

As shown in Table 4, a single cell in each component is selected to evaluate the contribution of decay heat to the total heat at the location with the highest neutron flux in the model. The first wall, blanket, back plate, shield and vacuum vessel are all placed at the equatorial module (indicated as “1” in Figure 1).

Table 4. Neutron flux and decay/prompt heat percentage in components.

\begin{tabular}{|c|c|c|c|c|c|c|}
\hline \multirow{2}{*}{ Component } & \multicolumn{5}{|c|}{ Decay/prompt heat at $1 \mathrm{~s}(\%)$} & \multirow{2}{*}{$\begin{array}{c}\text { Neutron Flux } \\
\left(1 / \mathrm{cm}^{2} / \mathrm{s}\right)\end{array}$} \\
\hline & $8 \mathrm{~h}$ & 1 mon & 6 mon & $30 \mathrm{y}$ & PPCS-B & \\
\hline First Wall & 14.2 & 16.6 & 17.2 & 18.7 & 20.9 & $8.2 E+14$ \\
\hline Blanket & 3.9 & 4.6 & 4.7 & 4.3 & 4.3 & $3.0 \mathrm{E}+14$ \\
\hline Back plate & 6.9 & 11.5 & 13.0 & 13.0 & 13.6 & $2.3 \mathrm{E}+13$ \\
\hline Shield & 9.9 & 16.5 & 18.6 & 19.0 & 20.2 & $1.0 \mathrm{E}+13$ \\
\hline Vessel & 2.0 & 2.9 & 2.9 & 3.0 & 3.1 & $1.4 \mathrm{E}+12$ \\
\hline \multicolumn{7}{|l|}{ Divertor } \\
\hline Armour & 9.0 & 21.3 & 23.2 & 48.7 & 55.9 & $6.7 \mathrm{E}+14$ \\
\hline Structure & 6.0 & 13.9 & 15.2 & 26.3 & 33.8 & $5.0 \mathrm{E}+14$ \\
\hline Base & 8.3 & 10.7 & 11.6 & 12.1 & 12.5 & $3.1 \mathrm{E}+14$ \\
\hline Support & 10.4 & 16.5 & 18.5 & 18.6 & 18.9 & $1.3 \mathrm{E}+14$ \\
\hline Shield & 11.9 & 19.6 & 22.1 & 22.4 & 23.3 & $4.8 \mathrm{E}+13$ \\
\hline
\end{tabular}


As the major energy carrier, the blanket does not produce a significant amount of decay heat. However, the decay heat in the divertor armour becomes very important at longer irradiation times.

\section{Conclusion}

Based on a reference design of the HCPB DEMO fusion reactor, proposed by CCFE in 2009, preliminary analyses are carried out to evaluate decay heat. In this work, when only prompt neutrons and gammas are considered, it is evaluated that an energy multiplication factor is 1.39 relative to a neutron power of $2.16 \mathrm{GW}$, which is $80 \%$ of the total fusion power of $2.7 \mathrm{GW}$. The total decay heat generated by activated materials is (relative to the total fusion power) $<3 \%$ at 1 second cooling time, $<1 \%$ at 1 day cooling time, and $<0.1 \%$ at 1 year cooling time. As a result, the decay heats are not particularly significant in terms of the overall energy multiplication in this tokamak device, but are important for safety studies, especially in some local regions. The ratio of decay heat to prompt heat in the divertor armour, however, can be as high as $10 \%$ and up to $~ 48.7 \%$ in one particular region with the highest neutron flux. These results correspond to an assumed 30 year operational lifetime of the device with $50 \%$ availability. In all calculations, the decay heat is estimated after the reactor is shutdown. The decay heat also exists whilst the reactor is still operational. Thus it is important to assess decay heat in such power calculations. This study suggests that the material selection has a significant impact on decay heat. We will extend this study to other materials such as tungsten FW armour and other breeding materials.

\section{Acknowledgements}

This work was jointly funded by the RCUK Energy Programme and EURATOM. The view and opinions expressed herein do not necessarily reflect those of the European Commission.

\section{References}

[1] U. Fischer, D. Große, P. Pereslavtsev, S. Stickel, H. Tsige-Tamirat and V.Weber, Neutronics design analyses of fusion power reactors based on a novel integral approach, Fusion Eng. Des. 84 (2009), pp. 323-328.

[2] L. El-Guebaly, P. Wilson, D. Henderson, M. Sawan, G. Sviatoslavsky, T. Tautges, R. Slaybaugh, B. Kiedrowski, A. Ibrahim, C. Martin, R. Raffray, S. Malang, J. Lyon, L.P. Ku, X. Wang, L. Bromberg, B. Merrill, L. Waganer, F. Najmabadi and the ARIES-CS Team, Designing ARIES-CS compact radial build and nuclear system: neutronics, shielding, and activation, Fusion Sci. and Technol. 54 (2008), pp. 747-770.
[3] L. El-Guebaly and The ARIES Team, ARIES-ST nuclear analysis and shield design, Fusion Eng. Des. 65 (2003), pp. 263-284.

[4] L. El-Guebaly and The ARIES Team, Overview of ARIES-RS neutronics and radiation shielding: key issues and main conclusions, Fusion Eng. Des. 38 (1997), pp. 139-158.

[5] D. Ward, private communication, CCFE internal memo, Reference Design for DEMO - Proposed 24/3/09.

[6] L. Giancarlia, M. Ferrarib, M.A. Fütterera and S. Malang, Candidate blanket concepts for a European fusion power plant study, Fusion Eng. Des. 49-50 (2000), pp. 445-456.

[7] R. Pampin and P. J. Karditsas, Fusion power plant performance analysis using the HERCULES code, Fusion Eng. Des. 81 (2006), pp. 1231-1237.

[8] MCNP5 Manual: MCNP - A General Monte Carlo $N$-Particle Transport Code, Version 5, Los Alamos National Laboratory, (2003).

[9] R.A. Forrest, FISPACT 2007 User Manual, UKAEA report FUS 534, United Kingdom Atomic Energy Authority, (2007).

[10]D. L. Aldama and A.Trkov, FENDL-2.1: Update of an Evaluated Nuclear Data Library for Fusion Applications, INDC(NDS)-467, IAEA, (2004).

[11]R.A. Forrest, J. Kopecky and J.-Ch. Sublet, EASY-2007: European Activation System, UKAEA report FUS 535, United Kingdom Atomic Energy Authority, (2007).

[12] J. Lucas, M. Cortés, P. Méndez, J. Hayward and D. Maisonnier, Energy storage system for a pulsed DEMO, Fusion Eng. Des. 82 (2007), pp. 2752-2757.

[13] D.A. Ehst, Y. Cha, A.M. Hassanein, S. Majumdar, B. Misra and H.C. Stevens, A comparison of pulsed and steady-state Tokamak reactor burn cycles, Part I: thermal effects and lifetime limitations, Nuclear Eng. and Des./Fusion 2 (1985), pp. 305-318.

[14]D.A. Ehst, J.N. Brooks, K. Evans Jr. and S. Kim, A comparison of pulsed and steady-state Tokamak reactor burn cycles, Part II: magnet fatigue, power supplies, and cost analysis, Nuclear Eng. and Des./Fusion 2 (1985), pp. 319-336.

[15]D. Maisonnier, D. Campbell, I. Cook, L. Di Pace, L. Giancarli, J. Hayward, A. Li Puma, M. Medrano, P. Norajitra, M. Roccella, P. Sardain, M.Q. Tran and D. Ward, Power plant conceptual studies in Europe, Nuclear Fusion 47 (2007), pp. 1524-1532.

[16] I. Cook, N. Taylor and D. Ward, The role of DEMO in a fast-track development of fusion power, IAEA Technical Meeting on First Generation of Fusion Power Plants, Vienna, July 2005.

[17]D. Maisonnier, I. Cook, P. Sardain, R. Andreani, L. Di Pace, R. Forrest, L. Giancarli, S. Hermsmeyer, P. Norajitra, N. Taylor and D. Ward, Final report of the European power plant conceptual study, EFDA-RP-RE-50, the European Fusion Development Agreement, (2005). 